Article

\title{
An Uncertainty Assessment of Human Health Risk for Toxic Trace Elements Using a Sequential Indicator Simulation in Farmland Soils
}

\author{
Hao Yang ${ }^{1,2,3}$, Yingqiang Song ${ }^{1}$, A-Xing Zhu ${ }^{4} \mathbb{D}$, Yueming $\mathrm{Hu}^{1,2,3,5,6, *}$ and Bo $\mathrm{Li}^{1,5,7}$ \\ 1 College of Natural Resources and Environment, South China Agricultural University, Guangzhou 510642, \\ China; yanghao21@stu.scau.edu.cn (H.Y.); yingq_s@stu.scau.edu.cn (Y.S.); bli@cse.ust.hk (B.L.) \\ 2 Guangdong Province Engineering Research Center for Land Information Technology, \\ Guangzhou 510642, China \\ 3 Key Laboratory of Construction Land Transformation, Ministry of Natural Resources, \\ Guangzhou 510642, China \\ 4 Department of Geography, University of Wisconsin-Madison, Madison, WI 53706, USA; azhu@wisc.edu \\ 5 South China Academy of Natural Resources Science and Technology, Guangzhou 510630, China \\ 6 Guangdong Province Key Laboratory for Land Use and Consolidation, Guangzhou 510642, China \\ 7 Department of Computer Science and Engineering, Hong Kong University of Science and Technology, \\ Hong Kong 999077, China \\ * Correspondence: ymhu@scau.edu.cn
}

Received: 24 April 2020; Accepted: 5 May 2020; Published: 8 May 2020

check for updates

\begin{abstract}
Toxic trace elements in farmland soils are potential threats to human health. In this study, we collected soil samples from the farmlands of southern Guangzhou. We used a sequential indicator simulation (SIS) to deal with the problem of skewed distribution in the sample data. We assessed the human health risks, as well as the uncertainties, of five toxic trace elements: arsenic (As), cadmium $(\mathrm{Cd})$, chromium $(\mathrm{Cr})$, lead $(\mathrm{Pb})$, and mercury $(\mathrm{Hg})$. The results were as follows: (1) The risk indices of two trace elements $(\mathrm{Cd}$ and $\mathrm{Hg}$ ) were less than the standard threshold, which means that there was no human health risk due to $\mathrm{Cd}$ and $\mathrm{Hg}$ in the study area. However, the maximum risk indices of As, $\mathrm{Cr}$, and $\mathrm{Pb}$ exceeded the standard threshold. In particular, the maximum risk index of $\mathrm{Pb}$ was twice the standard threshold; (2) The risk probabilities of As and Cr were less than 25\% in most areas, and only a few parcels of farmland have a $100 \%$ risk probability. The risk map of $\mathrm{Pb}$ was used to identify contiguous areas of high-risk probability (i.e., $75 \%-100 \%$ ) in the center of the study area. (3) E-type estimation by the SIS method overestimates the risk when the number of samples with concentrations above the threshold have a large proportion of total samples. Our conclusions are as follows: (1) The simulation results show that areas with high-risk indices were concentrated in the Panyu District, which is close to the Pearl River and the core urban area of Guangzhou; (2) Except for $\mathrm{Pb}$, these trace elements are not likely to pose health risks in southern Guangzhou; (3) This study considers the risk probability found with the SIS method to be more reliable for visualizing regional risk.
\end{abstract}

Keywords: toxic trace elements; sequential indicator simulation; human health risk; farmland; risk mapping

\section{Introduction}

As a common land-use type, farmland affects human well-being [1]. However, with the rapid development of urbanization and industrialization, toxic trace elements may contaminate farmland soils through diverse ways, such as irrigation, deposition, and runoff [2]. Toxic trace elements in contaminated 
farmland can easily enter the human body through breathing, skin contact, and food intake [3], which can result in lesions or cancerous changes in the human body [4]. For example, cadmium (Cd) intake can cause diseases such as lung cancer, kidney dysfunction, and high blood pressure [5]. Lead $(\mathrm{Pb})$ intake can cause symptoms such as lead poisoning, anemia, kidney disease, and gastrointestinal cramps [6]. Hexavalent chromium ( $\mathrm{Cr}$ ) is a recognized carcinogen [7]. The body's central nervous system is affected negatively by arsenic (As) and mercury $(\mathrm{Hg})$ intake $[8,9]$. The long-term accumulation of toxic trace elements in farmland comprises a major threat to human health. Regional health risk status of toxic trace elements are important for the protection of human health, food security, and farmland environments [10]. In order to obtain regional health risks accurately and effectively, it is important to quantify trace element toxicity [11]. Human health risk assessment is a key method for risk quantification $[12,13]$, which can help in the management of health risks, pollution warnings, and soil restoration [14].

Human health risk assessment calculates the risk of toxic trace elements by using the elemental concentrations of the samples $[11,15]$. There are two types of methods for human health risk assessment: methods based on deterministic models and methods based on stochastic models.

The first type of method is based on deterministic models. These methods construct a risk assessment model using the mechanisms of the exposure pathway, dose-response relationship, and crop reflection relationship. This type of model obtains the required parameters by referring to relevant institutional guidelines or scholarly research. Then, the health risk of the study area is calculated by the average hazard index with the soil trace element concentrations at the sampling points [16,17]. For example, Gu et al. [18] referred to the manual exposure factors and parameters in the technical guidelines for contaminated site risk assessment [19], in order to obtain human health risk assessments in 28 urban parks in Guangzhou. They calculated the average hazard index of the carcinogenic and non-carcinogenic risk of each park and concluded that no human health risk existed in the urban parks in Guangzhou. Sawut et al. [7] used a series of existing studies to determine the intake rate, intake time, and other parameters of trace elements. They calculated average hazard indices for both children and adults, and obtained the human health risks of vegetables in Northwest China. However, due to the individual differences of soil environmental variables and a lack of prior knowledge, trace element concentrations may have a high degree of spatial variability. The parameters of this model, therefore, have considerable uncertainty. Most of these parameters are determined directly by referring to existing guidelines or research. Moreover, the researchers calculated the average value of the hazard index to obtain the degree of regional risk, which may lead to smoothing effects. This method might overestimate or underestimate the risk. Some researchers have estimated the regional risk without considering the uncertainties involved [20].

The second type of method is based on stochastic models. These methods use stochastic simulation to calculate the uncertainty of the model parameters for human health risk assessment [21,22]. The stochastic simulation takes values randomly based on the cumulative distribution of the variable data, and produces multiple simulation results to obtain the risk and its uncertainty [23]. For example, Chen et al. [20] used a Monte Carlo simulation to solve the parameter uncertainty problem caused by a lack of prior knowledge when evaluating human health risk in the surface soil of Beijing. They obtained the human health risk situation and its uncertainty in the Beijing sampling area. Albuquerque et al. [24] used a sequential Gaussian simulation to obtain the uncertainty of the high and low-risk areas while studying the risk levels of 14 trace elements in the Aviles Estuary in Spain, and visualized the risk using a mean value map. However, data conforming to a normal distribution is a requirement for these methods. For instance, a Monte Carlo simulation may lead to more errors when the number of samples is not sufficient or the probability distribution is biased. In addition, a sequential Gaussian simulation loses information when the data are processed and transformed.

Human health risk assessment based on the uncertainty model can objectively reflect the risk of toxic trace elements. However, the current uncertainty model research is based on the condition that the frequency distribution of the sample data follow a normal distribution. Meeting the normal 
distribution requirements may be difficult when using sample data of trace elements in farmland, especially when the trace element concentrations have abnormal values. Simple abnormal value processing methods are prone to smoothing effects, which results in the loss of information in key areas [14,25]. Moreover, due to the cost limitations of sampling, the number of samples is often limited. Abnormal values influence the frequency distribution, but often contain information about contamination by toxic trace elements. Therefore, we cannot simply eliminate the abnormal values. Therefore, we need to study the use of uncertainty models in obtaining human health risk when the frequency distribution of the sample data has a non-normal distribution.

To obtain the human health risk of toxic trace elements in farmland, this study uses a non-parametric statistical sequential indicator simulation method to address the problem of the sample data frequency distribution. This study focuses on (1) simulating the regional farmland health risk of each trace element; (2) assessing their uncertainty; and (3) mapping the spatial distribution of the human health risk probability.

\section{Materials and Methods}

\subsection{Study Area}

The accumulation of toxic trace elements in farmland, especially around megacities, may result in a high probability of human health risks $[18,20]$. Guangzhou, a rapidly growing city, is one of the largest cities in South China. Guangzhou is located in the center of Guangdong Province, and is adjacent to Hong Kong and Macau. Guangzhou has a maritime subtropical monsoon climate, with an annual average temperature of $22.8^{\circ} \mathrm{C}$ and average annual precipitation of $1800 \mathrm{~mm}$. The Pearl River system passes through Guangzhou. It has a population of over 20 million. Human activity has a huge impact on this city. Due to the high degree of urbanization, few farmlands remain in the main urban areas of Guangzhou. Therefore, we selected the southern part of Guangzhou (i.e., Panyu and Nansha District) as the study area in this study, which has a lower urbanization level and contiguous farmland.

\subsection{Soil Sampling and Laboratory Analysis}

We designed the sampling plan according to land use/cover data of the study area. We sampled in the farmland as evenly as possible, with 195 samples $(0-20 \mathrm{~cm})$ throughout the farmland in 2015 . Figure 1 shows the spatial distribution of the sample points.
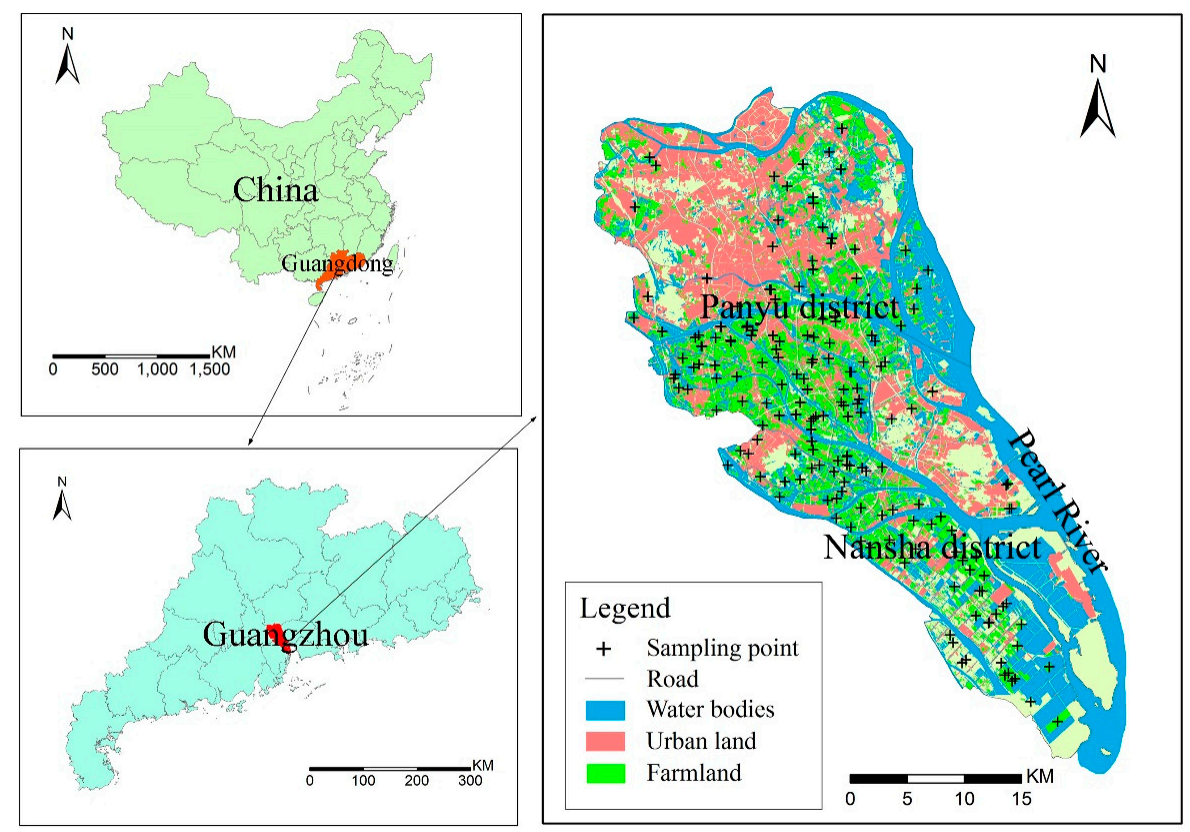

Figure 1. Sample point spatial distribution map. 
In this study, the selection of trace elements was based on the existing toxic trace element contamination research of Guangzhou [26-28]; we also refer to the "12th Five-Year Plan for Heavy Metals Contamination Comprehensive Prevention and Control" of China, and the "13th Five-Year Plan for Heavy Metals Contamination Comprehensive Prevention and Control" of Guangdong Province. We selected five trace elements for study: lead $(\mathrm{Pb})$, cadmium $(\mathrm{Cd})$, chromium $(\mathrm{Cr})$, mercury $(\mathrm{Hg})$, and arsenic (As). We determined the total amounts of these five trace elements. We used the $\mathrm{HF}-\mathrm{HNO}_{3}-\mathrm{HClO}_{4}$ digestion method to process lead $(\mathrm{Pb})$, cadmium $(\mathrm{Cd})$, and chromium $(\mathrm{Cr})$. We determined $\mathrm{Cd}$ and $\mathrm{Pb}$ by graphite furnace atomic absorption spectrometry and we determined $\mathrm{Cr}$ by flame atomic absorption spectrophotometry. The atomic absorption spectrometer (graphite furnace) used was the Z-2000 (HITACHI). The flame atomic absorption spectrometer used was the Z-5300 (HITACHI). Arsenic (As) and mercury ( $\mathrm{Hg}$ ) were processed with $\mathrm{HCl}-\mathrm{HNO}_{3}$ and were determined by reduction-gasification atomic fluorometry. The atomic fluorescence photometer used was the AFS-930 double-pipe atomic fluorescence spectrometer (Beijing Titan Instruments).

\subsection{Uncertainty Assessment of Human Health Risks}

\subsubsection{Sequential Indicator Simulation of Soil Data}

Sequential indicator simulation is a stochastic simulation method based on non-parametric statistics. Its indicator model has good flexibility and does not require the data used to satisfy any certain distribution type [29-31]. Moreover, the simulation has a small smoothing effect. This method does not ignore abnormal values in areas, which makes the simulation result closer to the real situation [14]. Information about the extreme values in the abnormal region can be utilized [32].According to the existing research, SIS can be divided into the following four steps [29]:

(1) The original sampled data are indicator transformed. The user obtains a priori conditional cumulative distribution function (CCDF) according to the Kriging method. $\left\{Z\left(x_{i}\right), i=1,2, \ldots, n\right\}$ is a set of sampled data under the K-group threshold $\left(\mathrm{z}_{\mathrm{k}}\right)$. The more quantiles (thresholds) that are selected, the more reliable the CCDF is [33]. The indicator variables are encoded as 0 or 1 by the indicator function $\mathrm{I}\left(\mathrm{x}_{\mathrm{i}}\right)$ (Equation (1)) [29]:

$$
\mathrm{I}\left(\mathrm{x}_{\mathrm{i}}\right)=\left\{\begin{array}{ll}
1, & \mathrm{x} \leq \mathrm{z}_{\mathrm{k}} \\
0, & \mathrm{x}>\mathrm{z}_{\mathrm{k}}
\end{array} \quad(\mathrm{k}=1,2, \ldots, K) .\right.
$$

(2) Using the known raw data as conditional data, the user obtains the conditional prior probability $\mathrm{F}(x)=Z\left(x_{i}\right) \leq z_{k} \mid C\left(x_{i}\right)$. This probability uses the indicator Kriging estimate to extrapolate its conditional cumulative distribution function $\mathrm{F}_{\mathrm{z}(\mathrm{x})}$.

(3) The user divides the study area into grids of uniform resolution and defines a random path through all grid nodes. This method extracts a value from $\mathrm{F}_{\mathrm{z}(\mathrm{x})}$ randomly as the simulation value at the first grid position. Then, the user obtains the estimated value $\hat{I}$ of the CCDF at the target grid (Equations (2)) [29]:

$$
\hat{I}\left(x_{0} ; z_{k}\right)=\operatorname{Prob}^{*}\left(Z\left(x_{i}\right) \leq z_{k} \mid C\left(x_{i}\right)\right) .
$$

(4) The above new value is added to the conditional data set. The grid's prior condition cumulative distribution function $\mathrm{F}_{\mathrm{z}(\mathrm{x})}$ for the next simulation position is modeled by this new data set. This process is repeated until all grid nodes are simulated.

This method obtains $\mathrm{n}$ realizations by repeating the above-mentioned steps. In $\mathrm{n}$ realizations, the number of grid values exceeding the threshold is $\mathrm{n}_{1}$ and the uncertainty (above threshold probability) of this grid is $n_{1} / n$. Each realization of the sequential indicator simulation has equal probability [25,32]. Some studies have also used conditional means (E-type estimate) of $\mathrm{n}$ realizations to obtain the spatial distribution of trace element concentrations [29-31]. In the calculation process, we used the GS + 9.0 software to obtain the experimental semivariogram and variogram models of each threshold. We realized the stochastic simulation with the SGeMS v2.5b software. 


\subsubsection{Human Health Risk Assessment}

Human health risks contain carcinogenic and non-carcinogenic risks. Toxic trace elements enter into the human body in different ways, such as oral intake, skin contact, and inhalation [34]. Existing research has demonstrated that As and $\mathrm{Cd}$ have carcinogenic effects [35]. Hexavalent chromium $\left(\mathrm{Cr}^{6+}\right)$ is carcinogenic to humans, but trivalent chromium $\left(\mathrm{Cr}^{3+}\right)$ has not been defined as being carcinogenic yet [35]. However, $\mathrm{Cr}^{6+}$ is more unstable than $\mathrm{Cr}^{3+}$ in nature [36]. Chromium in the soil is more inclined towards the stable state of $\mathrm{Cr}^{3+}$ [37]. Therefore, the reference parameter is the parameter of $\mathrm{Cr}^{3+}$ in this study, and we only consider the non-carcinogenic risk of $\mathrm{Cr}$. The non-carcinogenic assessment of trace elements include $\mathrm{Hg}, \mathrm{Pb}$, and $\mathrm{Cr}$. We used an exposure model based on the US EPA model [38]. The equations (Table A1) and parameters (Tables A2 and A3) refer to the Technical Guidelines For Risk Assessment of Contaminated Sites and Regional Screening Levels $[19,38]$. Due to the different dietary and living habits of people in different countries, the exposure parameters of health risk are different. The Technical Guidelines For Risk Assessment of Contaminated Sites was used to correct some parameters, according to the actual situation in China [19].

This study takes into account the effects of toxic trace elements on adults and children. The tolerance value for carcinogenic risk (CR) is $<10^{-4}[19,38]$. A non-carcinogenic hazard index (HI) below 1.0 indicates the absence of non-carcinogenic health risk [19,38]. We used the ArcGIS 10.2 software to visualize the risk. The risk assessment model (Equations (3)-(10)) was as follows [19,38]:

(1) Carcinogenic:

$$
\begin{gathered}
\text { Oral risk : } C R_{o i s}=\operatorname{OISER}_{c a} \times C_{s u r} \times S F_{o} \\
\text { Dermal risk : } C R_{d c s}=D C S E R_{c a} \times C_{s u r} \times S F_{d} \\
\text { Inhalational risk : } C R_{p i s}=P I S E R_{c a} \times C_{s u r} \times S F_{i} \\
\text { Carcinogenic risk : } C R_{n}=C R_{o i s}+C R_{d c s}+C R_{p i s}
\end{gathered}
$$

(2) Non-carcinogenic:

$$
\begin{gathered}
\text { Oral risk : } H Q_{o i s}=\operatorname{OISER}_{n c} \times C_{s u r} /\left(\boldsymbol{R} f D_{o} \times S A F\right) \\
\text { Dermal risk : } H Q_{d c s}=D C S E R_{n c} \times C_{s u r} /\left(R f D_{d} \times S A F\right) \\
\text { Inhalational risk : } H Q_{p i s}=P I S E R_{n c} \times C_{s u r} /\left(R f D_{i} \times S A F\right) \\
\text { Non - carcinogenic risk : } H I_{n}=H Q_{o i s}+H Q_{d c s}+H Q_{p i s} .
\end{gathered}
$$

\subsubsection{Uncertainty Model Accuracy Evaluation}

The accuracy of the uncertainty model was evaluated by the symmetric p-probability intervals (p-PI) [29]. The conditional cumulative probability distribution function $F(u ; \zeta)$ at any location $u$ allows for the computation of $\mathrm{p}$-PI bounded by $(1-\mathrm{p}) / 2$ and $(1+\mathrm{p}) / 2$. For example, the 0.5 -PI representation is $\left[F^{-1}(u ; 0.25), F^{-1}(u ; 0.75)\right]$. In this case, the correct uncertainty model would show that there is a 0.5 probability that the actual observations at $u$ falls into this interval [29]. We calculated the probability that an observation falls into p-PIs as follows (Equations (11) and (12)) [29]:

$$
\begin{gathered}
\bar{\zeta}(p)=1 / N \times \sum_{j=1}^{N} \zeta\left(u_{j} ; p\right),(j=1, \ldots, N ; N=195) . \\
\zeta\left(u_{j} ; p\right)=\left\{\begin{array}{c}
1 \text { if } F^{-1}\left(u_{j} ;(1-p) / 2\right)<Z\left(u_{j}\right)<F^{-1}\left(u_{j} ;(1+p) / 2\right) . \\
0 \text { otherwise }
\end{array}\right.
\end{gathered}
$$


A smaller root mean square error (RMSE) means higher accuracy [39]. The RMSE was calculated as follows (Equation (13)) [39]:

$$
\operatorname{RMSE}=\sqrt{1 / n \times \sum_{i=1}^{n}\left[p_{i}-\bar{\zeta}(p)\right]^{2}}(i=1, \ldots, n ; n=195) .
$$

\section{Results and Discussion}

\subsection{Preliminary Data Description}

Table 1 shows the results of the descriptive statistics of five trace elements in southern Guangzhou farmland.

Table 1. General descriptive statistics of each trace element.

\begin{tabular}{cccccccccc}
\hline Element & $\begin{array}{c}\text { Mean } \\
(\mathbf{m g} / \mathbf{k g})\end{array}$ & $\begin{array}{c}\text { Minimum } \\
\mathbf{( m g} / \mathbf{k g})\end{array}$ & $\begin{array}{c}\text { Maximum } \\
\mathbf{( m g} / \mathbf{k g})\end{array}$ & $\begin{array}{c}\text { Standard } \\
\text { Deviation } \\
\mathbf{( m g} / \mathbf{k g})\end{array}$ & Skewness & Kurtosis & $\begin{array}{c}\text { Coefficient } \\
\text { of Variation }\end{array}$ & $\begin{array}{c}\text { Background } \\
\text { Value } \\
\mathbf{( m g} / \mathbf{k g})\end{array}$ & $\begin{array}{c}\text { Kolmogorov- } \\
\text { Smirnov } \\
\text { Significance }\end{array}$ \\
\hline $\mathrm{Cd}$ & 0.18 & 0.05 & 0.48 & 0.06 & 0.58 & 1.53 & $36 \%$ & 0.11 & $3.60 \times 10^{-1}$ \\
$\mathrm{Hg}$ & 0.13 & 0.03 & 0.46 & 0.08 & 1.59 & 2.02 & $63 \%$ & 0.13 & 0 \\
$\mathrm{As}$ & 10.30 & 0.66 & 42.62 & 8.34 & 1.67 & 2.89 & $81 \%$ & 25 & $8.28 \times 10^{-5}$ \\
$\mathrm{~Pb}$ & 51.75 & 19.10 & 122.00 & 16.48 & 1.47 & 3.87 & $32 \%$ & 60 & $1.39 \times 10^{-2}$ \\
$\mathrm{Cr}$ & 69.74 & 20.83 & 156.47 & 22.63 & 0.22 & 0.23 & $32 \%$ & 77 & $3.57 \times 10^{-1}$ \\
\hline
\end{tabular}

Note: Kolmogorov Smirnov significance less than 0.05 means that the data do not meet the normal distribution.

The main soil types of farmland were paddy soils and red soils in study area. The main soil texture was loam. The clay content was in the range of $22 \%-43 \%$. The maximum, average, and minimum $\mathrm{pH}$ values were 8.2, 5.7, and 3.9, respectively. By comparing the background values of risk screening values for soil trace elements of the Pearl River Delta area [40], the maximum values of the five trace elements were seen to be higher than the soil background values. This indicated that trace elements have external inputs in the study area. Furthermore, the average values for $\mathrm{Cd}$ and $\mathrm{Hg}$ were larger than the soil background values, indicating that the $\mathrm{Cd}$ and $\mathrm{Hg}$ accumulation was high. Previous studies have found that urban land and mining areas had contamination of toxic trace elements in Guangzhou [18]. Soil trace elements of farmland in Guangzhou are likely to pose risks to crops, humans, and the environment. Due to the high urbanization development in Guangzhou, as seen in Figure 1, farmland in the Panyu and Nansha Districts is very close to urban areas. Therefore, studies of the human health risks of toxic trace elements in this farmland has been deemed necessary.

The coefficient of variation (CV) is the ratio of the standard deviation to the mean [41]. The CV reflects the degree of dispersion of variables. The coefficient of variation of the five trace elements was in the range of $32 \%-81 \%$. The order of variation was $\mathrm{As}>\mathrm{Hg}>\mathrm{Cd}>\mathrm{Cr}=\mathrm{Pb}$. The coefficients of variation of As and $\mathrm{Hg}$ were relatively large, indicating that these two trace elements may be greatly affected by human activity. The asymmetry coefficients (skewness) of the five trace elements were all greater than 0 , as can be seen in Table 1; therefore, their data frequency distributions had a certain positive bias. The order of deviation was $\mathrm{As}>\mathrm{Hg}>\mathrm{Pb}>\mathrm{Cd}>\mathrm{Cr}$. The Kolmogorov-Smirnov (K-S) test showed that As and $\mathrm{Hg}$ had a significance of less than 0.05 , which means that their data distribution was not normal. We could not use those data to provide a good result with some uncertainty models, such as Monte Carlo or a sequential Gaussian simulation [42].

\subsection{Uncertainty Assessment of Human Health Risk Based on SIS}

\subsubsection{Human health Risk Threshold of Each Trace Element}

We used the concentrations of trace elements to calculate human health risks at each sample point. Then, we calculated the average values of sample points to obtain the human health risk indices (CR or $\mathrm{HI})$ for the five trace elements. According to the risk standard value, a cancer risk index (CR) below $10^{-4}$ is acceptable, and the non-carcinogenic hazard index (HI) indicates no hazard when it has a value 
less than 1.0. As shown in Table 2, the CR of As and Cd were less than $10^{-4}$, and the $\mathrm{HI}$ of $\mathrm{Hg}$, $\mathrm{Pb}$, and $\mathrm{Cr}$ were less than 1.0. This result meant that the carcinogenic risk of the study area was acceptable and non-carcinogenic hazards did not exist in the study area. However, this method may ignore the risk information of abnormal value of some samples.

Table 2. The cancer risk index (CR), non-carcinogenic hazard index (HI), and threshold of human health risk of each trace element.

\begin{tabular}{cccccc}
\hline & \multicolumn{2}{c}{ Carcinogenic Elements } & \multicolumn{2}{c}{ Non-Carcinogenic Elements } \\
\cline { 2 - 5 } & As & Cd & Hg & Pb & Cr \\
\hline CR (Mean) & $2.80 \times 10^{-5}$ & $6.94 \times 10^{-7}$ & - & - & - \\
HI (Mean) & - & - & 0.07 & 0.98 & 0.51 \\
Threshold (mg/kg) & 36.81 & 26.27 & 1.80 & 52.85 & 137.34 \\
\hline
\end{tabular}

According to these judgments and the US EPA's health risk model, we calculated the CR and $\mathrm{HI}$ risk thresholds for each trace element. The threshold of concentration of a carcinogenic trace element was calculated as $\mathrm{C}_{\text {sur }}=10^{-4}$ / (Oral risk factor + Dermal risk factor + Inhalational risk factor). The threshold of concentration of a non-carcinogenic trace element was calculated as $C_{\text {sur }}=1 /$ (Oral risk factor + Dermal risk factor + Inhalational risk factor). Table 2 shows those thresholds. As can be seen in Table 1, the concentrations of $\mathrm{As}, \mathrm{Pb}$, and $\mathrm{Cr}$ exceeded their risk thresholds. Therefore, certain risks existed in some areas of the study area.

\subsubsection{Human Health Risk Assessment Based on SIS}

We used the thresholds (Table 2) to perform a sequential indicator simulation. This method needs the a priori information of the corresponding indicator Kriging. As the distribution of sample points was non-uniform, we used the average nearest neighbor method to determine the step size. According to the rule of thumb, the number of steps is equal to half the maximum distance between pairs of sample points divided by the step size. We took the quartile of each trace element concentrations as the threshold value, and obtained experimental semivariogram and variogram models of each threshold condition. Table A4 lists the parameters of the experimental semivariograms and the fitted models for each trace element. According to the size of the study area and the operation time of grid division, we divided the study area into of $620 \times 510$ grid, where the size of each grid was $100 \mathrm{~m} \times 100 \mathrm{~m}$. We carried out 1000 realizations in each grid by SIS. Then, we obtained the risk index of CR or HI for each trace element by calculating the E-type estimates. The E-type estimates showed the spatial distribution of the risk index (Figure 2).

As shown by the risk index distribution map (Figure 2), the clusters with high values of each trace element were mostly concentrated in the north and central regions of the study area. These areas were mainly close to the Pearl River and the urban areas of the Panyu District (Figure 1). This showed that urban areas have an impact on trace elements of farmland around cities. The cancer risk index (CR) of As exceeded the threshold $\left(10^{-4}\right)$ in some areas. The cancer risk index (CR) of $\mathrm{Cd}$ did not exceed the threshold $\left(10^{-4}\right)$, which meant there was no risk of $\mathrm{Cd}$ in the study area. The maximum non-carcinogenic hazard index (HI) of $\mathrm{Cr}$ and $\mathrm{Pb}$ exceeded the threshold (1.0). In particular, the maximum non-carcinogenic $\mathrm{HI}$ of $\mathrm{Pb}$ was twice the standard threshold. The non-carcinogenic hazard index (HI) of $\mathrm{Hg}$ did not exceed the threshold (1.0), which meant there was no risk of $\mathrm{Hg}$ in the study area. According to the spatial distribution of risk index, the risk areas comprised only a small part of the study area. 


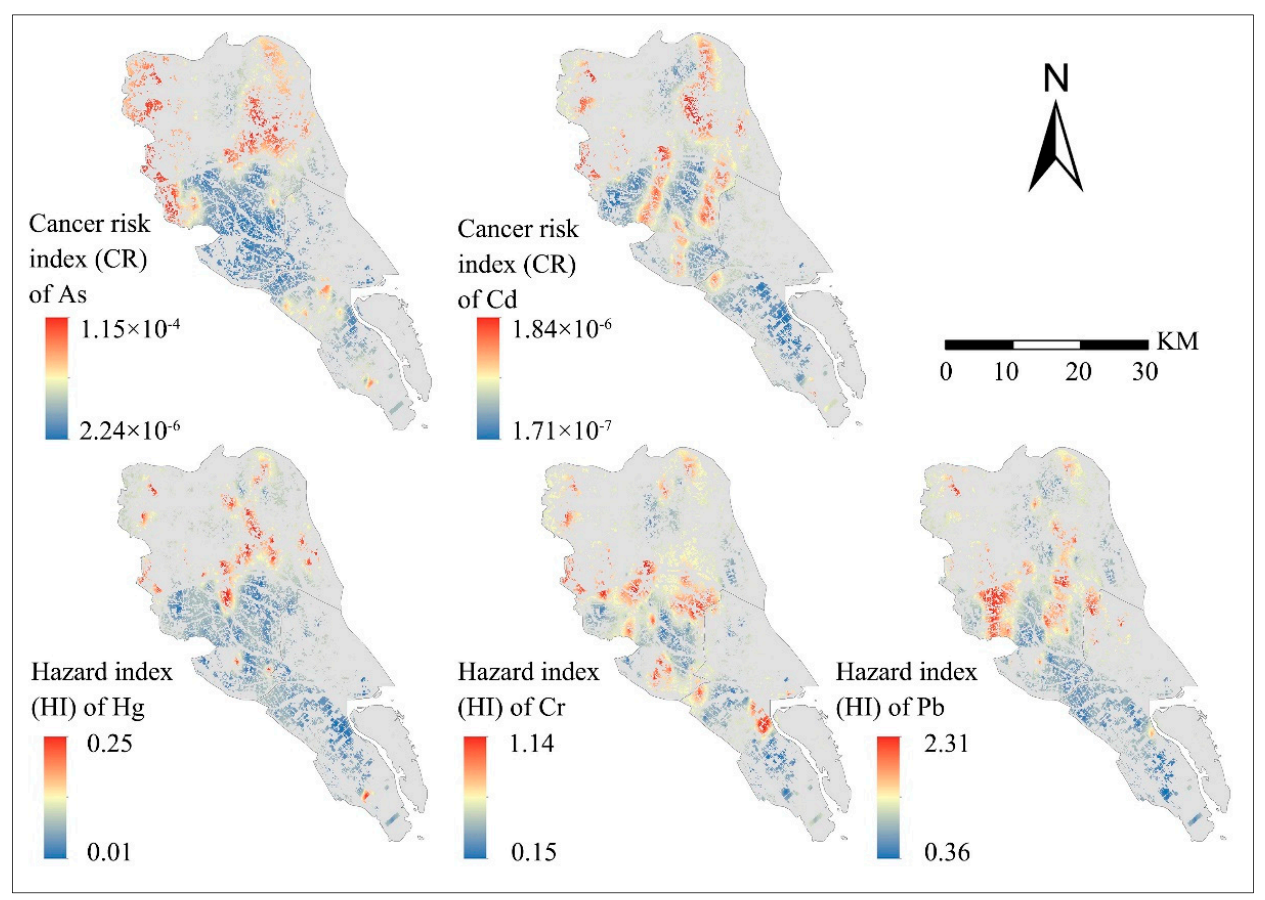

Figure 2. Spatial distribution of the cancer risk index (CR) or non-carcinogenic hazard index (HI) for each trace element.

\subsubsection{Uncertainty Assessment}

From the above-mentioned $\mathrm{CR}$ or $\mathrm{HI}$ of trace elements, $\mathrm{Cd}$ and $\mathrm{Hg}$ were unlikely to pose a risk to human health in the study area. However, the maximum risk values of $\mathrm{As}, \mathrm{Pb}$, and $\mathrm{Cr}$ exceeded the threshold. We calculated the probability of each grid exceeding the risk for $\mathrm{As}, \mathrm{Pb}$, and $\mathrm{Cr}$. The process was as follows: the risk threshold of each trace element was set as the criterion. Then, we counted the number $\left(\mathrm{n}_{1}\right)$ of each grid when the trace element concentration exceeded the risk threshold in $\mathrm{n}$ realizations; the risk probability of the grid was calculated with $p=n_{1} / n$. Figure 3 shows the spatial distribution of the risk probability.

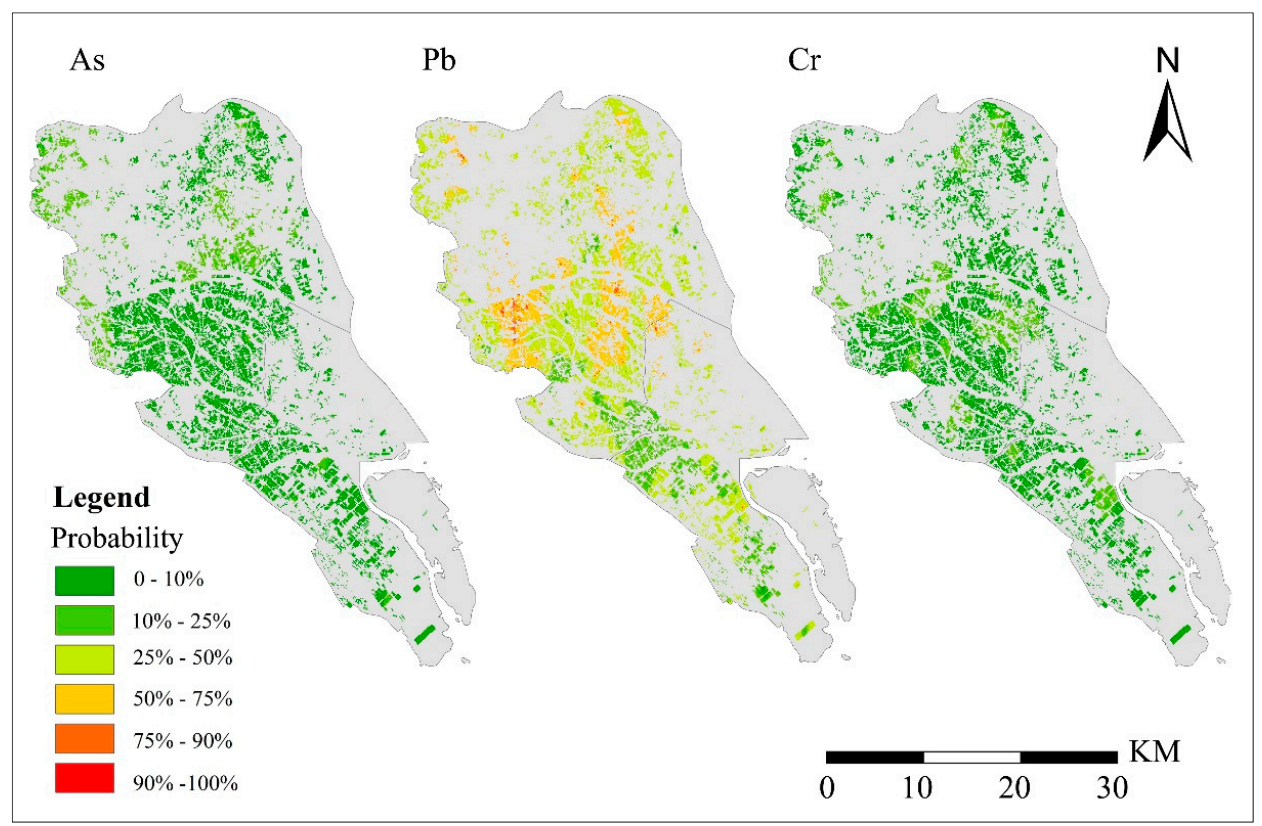

Figure 3. Spatial distribution for the risk probability of each trace element. 
Figure 3 shows that most of the risk probabilities of As and Cr ranged from $0 \%$ to $25 \%$, which indicates a low-risk level. However, areas of high-risk probability (75\% to $100 \%$ ) also existed. The $100 \%$ risk probabilities for As and $\mathrm{Cr}$ only existed in a few grids. According to the size of the grid, a few parcels of farmland had certain health risks. Therefore, the overall risks of As and $\mathrm{Cr}$ were acceptable in the study area. We should give much more attention to the at-risk farmlands. Figure 3 also shows the risk probability of $\mathrm{Pb}$. Most of the risk probabilities of $\mathrm{Pb}$ ranged from $25 \%$ to $50 \%$, which indicates a moderate-risk level. The high-risk probability (75\% to $100 \%$ ) areas of $\mathrm{Pb}$ were concentrated in the central part of the study area. Furthermore, areas of $100 \%$ risk probability of Pb existed in some grids. The management should give priority to and carry out monitoring in these farmlands.

According to the grid statistics (Figure 4), most risk possibilities of As and $\mathrm{Cr}$ were less than $25 \%$. Therefore, most areas were low-risk situations, which indicates that these trace elements were less likely to pose health risks in southern Guangzhou. The proportion of moderate-risk areas $(25 \%<$ probability $<75 \%$ ) for $\mathrm{Pb}$ was $80.06 \%$ in the study area. The proportion of high-risk areas (probability $>75 \%$ ) for $\mathrm{Pb}$ was $1.2 \%$, with an area of $2.8 \mathrm{~km}^{2}$. Therefore, the study area had a moderate-risk of $\mathrm{Pb}$. The risk probability can help to determine the key risk control areas of farmland. The management should set a certain monitoring threshold, and consider more sampling and analysis of toxic trace elements in these farmlands. It is necessary to take more protection measures in these farmlands.

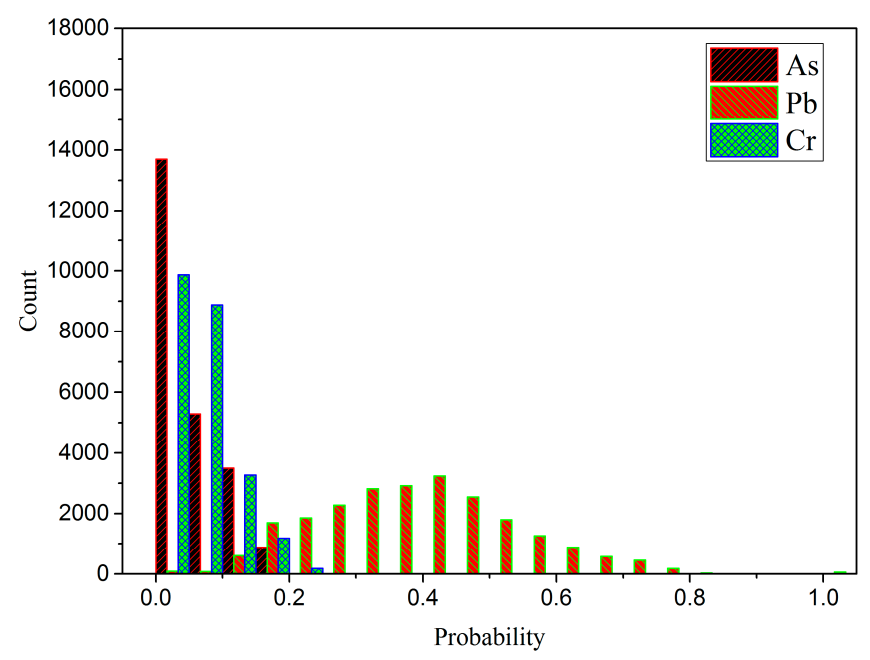

Figure 4. Grid statistics of risk probabilities of $\mathrm{As}, \mathrm{Pb}$, and $\mathrm{Cr}$.

\subsection{Accuracy Evaluation of the Uncertainty Model}

We evaluated the accuracy of the risk uncertainty. Nine p-PI intervals (" $10 \%$ ", " $20 \%$ ", " $30 \%$ ", " $40 \%$ ", " $50 \%$ ", “60\%", " $70 \%$ ", " $80 \%$ ", and " $90 \%$ ") were calculated to obtain the probability that the sample point fell into the $\mathrm{p}$ interval. The closer the scatter is to the standard line (i.e., $\mathrm{y}=\mathrm{x}$ ), the more accurate the result. The results in Figure 5 show the accuracy of the evaluation results for the risk probability (CR or $\mathrm{HI})$. The scattered lines are all close to the standard line. The RMSE level was also low: the RMSE of As, $\mathrm{Pb}$, and $\mathrm{Cr}$ were $0.0218,0.0208$, and 0.0211 , respectively. The RMSE indicated that the overall accuracy of the uncertainty evaluation was effective [39]. 


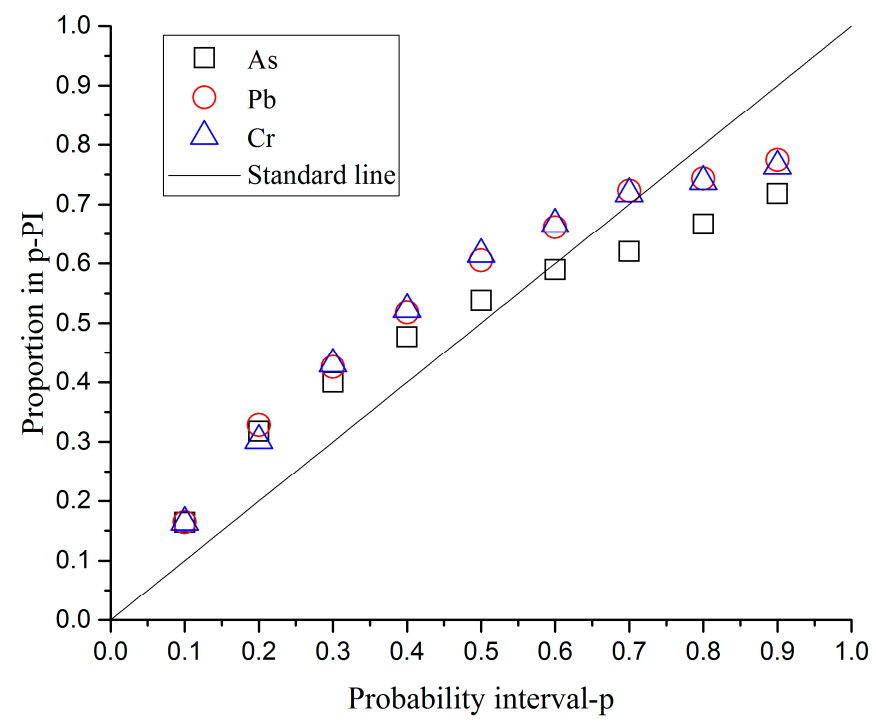

Figure 5. Scatter plot of p-PI and risk probability.

\subsection{Discussion}

\subsubsection{Comparison of Human Health Risk Results}

The coefficient variation (CV) of As was large, which means that the accumulation of As was mainly caused by human factors. The areas with high concentrations of As were close to the Pearl River basin in this study. The Panyu and Nansha District are delta areas where the sediments of the Pearl River accumulate, and the irrigation of the farmland in these areas depends on the Pearl River and its tributaries. The discharge of sewage and wastewater results in the increase of As concentrations in the Pearl River [43,44], which may cause the accumulation of As. At the same time, the productive process of Guangzhou's non-ferrous metal production is the main source of As in the atmosphere. Dust deposition has a negative impact on outdoors environments, and the CR of As has been found to exceed the threshold in urban areas of Guangzhou [45], which is consistent with the results of this study. However, we also found that most of the risk of As did not exceed the unacceptable level in farmland of Guangzhou, and the risk management can be strengthened according to the risk probability.

From the results of the risk assessment for $\mathrm{Cr}$, the risk probabilities of most farmlands were at a low-risk level (0\%-25\%). The health risk of $\mathrm{Cr}$ was found to be acceptable in Guangzhou City in other studies $[18,45,46]$, in accordance with the results of this study. Very few farmlands exhibited a high-risk situation, and the spatial distribution did not show any tendency for aggregation. Therefore, we should analyze the high-risk fields, in order to determine if they are associated with point-source pollution.

Traffic activities have been shown to have a serious impact on the $\mathrm{Pb}$ pollution in the urban surface soil of Guangzhou [28,47]. The concentration of $\mathrm{Pb}$ in the soil has been positively correlated with the traffic load of the road [48]. The spatial distribution of Pb's human health risk in farmland was scattered in this study. Most grids of risk probabilities (50\%-100\%) were near roads. In addition, most of these roads are expressways. Furthermore, Pb-containing substances enter the ground through industrial emission, coal combustion, and waste incineration $[49,50]$. Those problems also affect the farmland soil of this city. In this study, $\mathrm{Pb}$ is a toxic trace element which can pose health risks in some farmlands. Management should monitor the tendency of $\mathrm{Pb}$ accumulation to control the risk.

We found that there has no human health risk of $\mathrm{Cd}$ and $\mathrm{Hg}$ in the farmland soil of southern Guangzhou under the current conditions. In other studies on toxic trace elements in Guangzhou, the areas with high concentrations of $\mathrm{Cd}$ and $\mathrm{Hg}$ appeared in the core urban area of the city [51]. Those core urban areas are close to the north of the study area. At the same time, the human health risks of $\mathrm{Cd}$ and $\mathrm{Hg}$ in other studies were found to be acceptable for Guangzhou's urban environment and atmospheric particles $[18,52,53]$. These conclusions were similar to our results. 


\subsubsection{Selection of Risk Mapping Based on the SIS Method}

The SIS method can obtain the probability (above threshold) and conditional means (E-type estimate) for each variable grid [29]. Some studies have obtained the spatial distribution of regional trace element concentrations by using E-type estimates [3,14,31]. According to the risk threshold, the spatial distribution of regional trace element concentrations also can provide a reference for regional risk management [3,31].

We considered three kinds of numbers: the number of sample points whose sample concentration exceeded the risk threshold, the number of grids whose E-type estimated value exceeded the risk threshold, and the number of grids with $100 \%$ risk probability (Table 3 ). Combined with the spatial distribution of risk probability (Figure 3), locations of the sample concentration above the threshold were consistent with $100 \%$ risk probability locations. The numbers were equal or close for sample points and $100 \%$ risk probability grids. At the same time, the number and distribution (Figure 6) of over-risk grids (E-type estimate) of As and $\mathrm{Cr}$ were consistent with the over-risk sample point and the $100 \%$ risk probability grid. However, the number of over-risk grids (E-type estimate) of $\mathrm{Pb}$ were much greater than the $100 \%$ risk probability grid. This shows that these grids have a low risk probability but have a high E-type estimate value: which means that the high values in the grid have a small quantity, but a large contribution of the E-type estimate.

Table 3. Grid statistics for exceeding risk threshold of each trace element.

\begin{tabular}{cccc}
\hline Elements & Sample Point & $\begin{array}{c}\text { Grid Quantity } \\
(\mathbf{1 0 0 \% )}\end{array}$ & $\begin{array}{c}\text { Grid Quantity } \\
\text { (E-type) }\end{array}$ \\
\hline $\mathrm{As}$ & 3 & 3 & 3 \\
$\mathrm{Cr}$ & 1 & 1 & 1 \\
$\mathrm{~Pb}$ & 73 & 65 & 14,614 \\
\hline
\end{tabular}

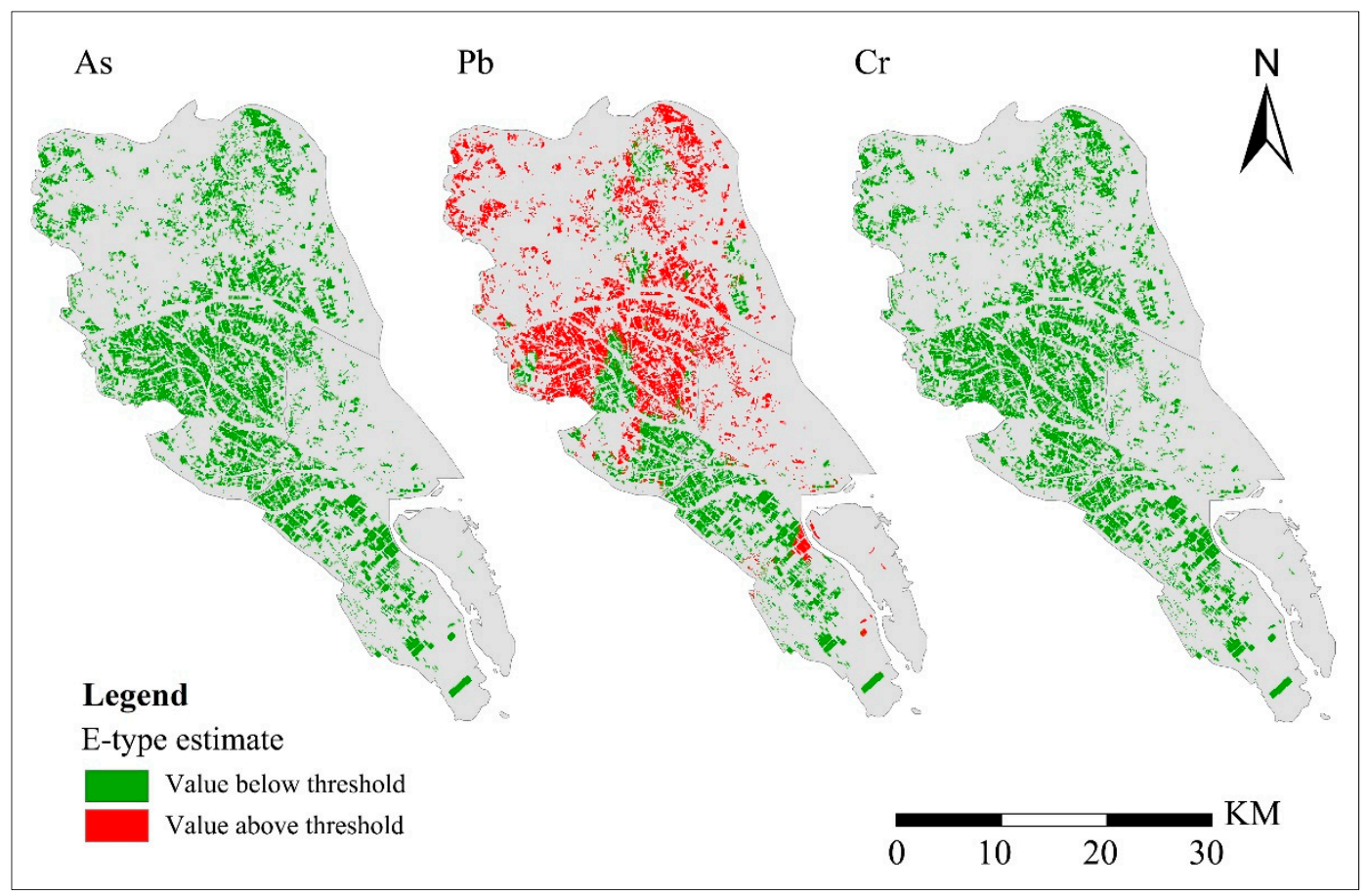

Figure 6. Spatial distribution of E-type estimate for risk threshold of each trace element.

The risk threshold may have an impact on the accuracy of risk judgement made by the E-type estimate. Before the calculation of the E-type estimate, the sample data is divided into sub-intervals by quantiles. We then multiply the subinterval probability by the average of the subinterval to obtain the 
E-type estimate. The average value of the sub-interval is calculated by the head and tail values of these sub-intervals [54-56]. The number of sampling points whose sample concentration $(\mathrm{Pb})$ exceeded the risk threshold was $42 \%$ of the total. We divided the $\mathrm{Pb}$ data into four sub-intervals (by quartile). We can see that the risk threshold was lower than the average of the third sub-interval (i.e., 2nd quartile to 3rd quartile). This is the reason why the E-type estimate is easily greater than the risk threshold. Therefore, when the number of samples with concentration above threshold has a large proportion of total sample amount, the E-type estimate overestimates the risk. Therefore, we tend to use the risk probability by using the SIS for risk judgement.

\section{Conclusions}

This study assessed the human health risks of toxic trace elements in the farmland of southern Guangzhou, a rapidly developing area of China. We also analyzed the risk uncertainty and visualized the regional risk probability. We drew the following conclusions.

The high-value areas of the human health risk index were concentrated in the north-central area (Panyun District) of the study area, which is close to the main urban area of Guangzhou, and has frequent human activities. We found that high urbanization poses a hazard to human health in farmland. We calculated the risk index of each trace element by using a risk assessment model of human health. The maximum risk indices of $\mathrm{Cd}$ and $\mathrm{Hg}$ were less than the standard threshold, while the maximum risk indices of $\mathrm{As}, \mathrm{Cr}$, and $\mathrm{Pb}$ exceeded the standard threshold. In particular, the maximum risk index of $\mathrm{Pb}$ was twice the standard threshold.

We visualized the risk uncertainty to obtain the risk probability distribution map. Most of the risk probabilities of As and $\mathrm{Cr}$ were between $0 \%$ and $25 \%$, which indicates a low-risk level. The $100 \%$ human health risk probability areas of As and Cr were only a few parcels of farmland. Most of the risk probabilities of $\mathrm{Pb}$ were between $25 \%$ and $50 \%$, which indicates a moderate-risk level. Some areas $\left(2.8 \mathrm{~km}^{2}\right)$ had a $100 \%$ probability health risk of $\mathrm{Pb}$; we should give more attention and take more protection measures for farmland in these areas. The RMSE of the risk uncertainty model was low. The order of RMSE was $\mathrm{As}>\mathrm{Pb}>\mathrm{Cr}$ and the accuracy of the uncertainty model was acceptable.

We found that the mean estimate using traditional methods may underestimate the human health risks. Moreover, the E-type estimate by the SIS method overestimated the human health risk when the number of samples with concentration above the threshold had a large proportion of total sample amount. Therefore, we suggest using the risk probability by the SIS method to visualize regional human health risks. Using the risk probability makes interpreting the risk situation more intuitive. It is relatively reliable and realistic, and can provide guidance for the prevention of toxic trace elements influencing human health.

Author Contributions: Conceptualization, H.Y. and Y.S.; methodology, H.Y.; software, H.Y.; validation, H.Y. and Y.S.; formal analysis, Y.S.; investigation, H.Y. and Y.S.; resources, Y.H.; data curation, B.L.; writing-original draft preparation, H.Y.; writing-review and editing, A.-X.Z.; visualization, H.Y.; supervision, Y.H.; project administration, Y.H.; funding acquisition, Y.H. All authors have read and agreed to the published version of the manuscript.

Funding: This work was supported by the National Key Research and Development Program of China (2016YFD0800301 and 2018YFD1100103) and the Science and Technology Program of Guangzhou, China (201804020034).

Acknowledgments: I would like to thank Han Zhang and Rongrong Ma for providing language assistance.

Conflicts of Interest: The authors declare no conflict of interest. 


\section{Appendix A}

Table A1. Equations of each parameter.

\begin{tabular}{|c|c|c|}
\hline Parameter & Type & Equation \\
\hline $\begin{array}{l}\text { Carcinogenic } \\
\text { exposure value }\end{array}$ & $\begin{array}{c}\text { Dermal } \\
\text { Inhalational }\end{array}$ & 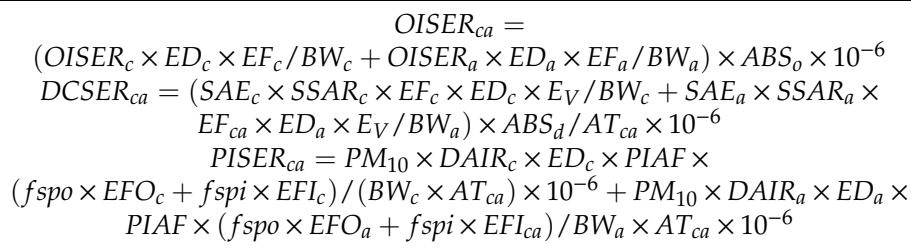 \\
\hline $\begin{array}{l}\text { Non-carcinogenic } \\
\text { exposure value }\end{array}$ & $\begin{array}{l}\text { Oral intake } \\
\text { Dermal } \\
\text { Inhalational }\end{array}$ & $\begin{array}{c}\text { OISER }_{n c}=\text { OISER }_{c} \times E D_{c} \times E F_{c} \times A B S_{o} / B W_{c} \times A T_{n c} \times 10^{-6} \\
D C S E R_{n c}=S A E_{c} \times S S A R_{c} \times E F_{c} \times E D_{c} \times E_{V} \times A B S_{d} / B W_{c} \times A T_{n c} \times 10^{-6} \\
P I S E R_{n c}=P M_{10} \times D A I R_{c} \times E D_{c} \times P I A F \times \\
\left(f_{s p o} \times E F O_{c}+f s p i \times E F I_{c}\right) / B W_{c} \times A T_{n c} \times 10^{-6}\end{array}$ \\
\hline
\end{tabular}

Note: OISER means oral ingestion of soil exposure. DCSER means soil exposure through skin contact routes. PISER means soil exposure to inhaled particulate matter.

Table A2. Values of each parameter.

\begin{tabular}{|c|c|c|c|c|}
\hline Parameter & Symbol & Units & Value & Reference \\
\hline Exposure duration of children & EDc & a & 6 & $($ MEPPRC, 2014) \\
\hline Exposure duration of adults & EDa & a & 24 & $($ MEPPRC, 2014) \\
\hline Exposure frequency of children & Efc & $d \cdot a^{-1}$ & 350 & $($ MEPPRC, 2014) \\
\hline Exposure frequency of adults & Efa & $d \cdot a^{-1}$ & 350 & $($ MEPPRC, 2014) \\
\hline Average body weight of children & BWc & $\mathrm{kg}$ & 56.8 & $($ MEPPRC, 2014) \\
\hline Average body weight of adults & Bwa & $\mathrm{kg}$ & 15.9 & $($ MEPPRC, 2014) \\
\hline Absorption factor of oral ingestion & ABSo & unitless & 1 & $($ MEPPRC, 2014) \\
\hline Average time for carcinogenic effect & ATca & $\mathrm{d}$ & 26,280 & $($ MEPPRC, 2014) \\
\hline Average time for non-carcinogenic effect & Atnc & $\mathrm{d}$ & 2190 & $($ MEPPRC, 2014) \\
\hline Exposed skin surface area of adults & SAEa & $\mathrm{cm}^{2}$ & 5074.89 & $($ MEPPRC, 2014) \\
\hline Exposed skin surface area of children & SAEc & $\mathrm{cm}^{2}$ & 2447.56 & $($ MEPPRC, 2014) \\
\hline Adherence rate of soil on skin for adults & SSARa & $\mathrm{mg} \cdot \mathrm{cm}^{-2}$ & 0.07 & $($ MEPPRC, 2014) \\
\hline Adherence rate of soil on skin for children & SSARc & $\mathrm{mg} \cdot \mathrm{cm}^{-2}$ & 0.2 & $($ MEPPRC, 2014) \\
\hline Daily exposure frequency of dermal contact event & Ev & times/d & 1 & $($ MEPPRC, 2014) \\
\hline Content of inhalable particulates in ambient air & $\mathrm{PM}^{10}$ & $\mathrm{mg} \cdot \mathrm{m}^{-3}$ & 0.15 & $($ MEPPRC, 2014) \\
\hline Daily air inhalation rate of adults & DAIRa & $\mathrm{m}^{3} \cdot \mathrm{d}^{-1}$ & 14.5 & $($ MEPPRC, 2014) \\
\hline Daily air inhalation rate of children & DAIRc & $\mathrm{m}^{3} \cdot \mathrm{d}^{-1}$ & 7.5 & $($ MEPPRC, 2014) \\
\hline Retention fraction of inhaled particulates in body & PIAF & unitless & 0.75 & $($ MEPPRC, 2014) \\
\hline Fraction of soil-borne particulates in indoor air & fspi & unitless & 0.8 & $($ MEPPRC, 2014) \\
\hline Fraction of soil-borne particulates in outdoor air & fspo & unitless & 0.5 & $($ MEPPRC, 2014) \\
\hline Indoor exposure frequency of adults & EFIa & $\mathrm{d} \cdot \mathrm{a}^{-1}$ & 262.5 & $($ MEPPRC, 2014) \\
\hline Indoor exposure frequency of children & EFIc & $d \cdot a^{-1}$ & 262.5 & $($ MEPPRC, 2014) \\
\hline Outdoor exposure frequency of adults & EFOa & $d \cdot a^{-1}$ & 87.5 & $($ MEPPRC, 2014) \\
\hline Outdoor exposure frequency of children & EFOc & $d \cdot a^{-1}$ & 87.5 & $($ MEPPRC, 2014) \\
\hline Soil allocation factor & SAF & unitless & 0.2 & $($ MEPPRC, 2014) \\
\hline Dermal absorption factor of $\mathrm{Cd}$ & $\mathrm{ABSD}_{\mathrm{Cd}}$ & unitless & 0.001 & $(\mathrm{USEPA}, 2013)^{\mathrm{b}}$ \\
\hline Dermal absorption factor of CR & $\mathrm{ABSD}_{\mathrm{Cr}}$ & unitless & 0.001 & $(\text { USEPA, 2013) })^{b}$ \\
\hline Dermal absorption factor of As & $\mathrm{ABSD}_{\mathrm{As}}$ & unitless & 0.03 & $(\text { USEPA, 2013) })^{b}$ \\
\hline Dermal absorption factor of $\mathrm{Hg}$ & $\mathrm{ABSD}_{\mathrm{Hg}}$ & unitless & 0.05 & $(\mathrm{HC}, 2004)^{\mathrm{c}}$ \\
\hline Dermal absorption factor of $\mathrm{Pb}$ & $\mathrm{ABSD}_{\mathrm{Pb}}$ & unitless & 0.006 & $(\mathrm{HC}, 2004)^{\mathrm{c}}$ \\
\hline
\end{tabular}

${ }^{a}$ Chinese MEP. (2014). Technical guidelines for risk assessment of contaminated sites (HJ25.3-2014, published in Chinese). China Environmental Science Press Beijing. ${ }^{b}$ USEPA. (2013). Regional Screening Levels (RSL) for Chemical Contaminants at Superfund Sites. Washington DC: USEPA. ${ }^{c}$ Health Canada. (2004). Federal Contaminated Site Risk Assessment in Canada-Part II: Health Canada Toxicological Reference Values (TRVs) and Chemical-Specific Factors. Ottawa. 
Table A3. Parameters for each trace element toxicity.

\begin{tabular}{cccccccc}
\hline Parameter & & $\begin{array}{c}\text { SFo } \\
\text { (mg/kg-day) }\end{array}$ & $\begin{array}{c}\text { SFd } \\
\text { (mg/kg-day) }\end{array}$ & $\begin{array}{c}\text { SFi } \\
\text { (mg/kg-day) }\end{array}$ & $\begin{array}{c}\text { RfDo } \\
\text { (mg/kg-day) }\end{array}$ & $\begin{array}{c}\text { RfDd } \\
\text { (mg/kg-day) }\end{array}$ & $\begin{array}{c}\text { RfDi } \\
\text { (mg/kg-day) }\end{array}$ \\
\hline $\begin{array}{c}\text { Carcinogenic } \\
\text { Elements }\end{array}$ & $\mathrm{As}$ & 1.50 & 1.50 & 16.84 & - & - & - \\
\hline \multirow{2}{*}{$\begin{array}{c}\text { Non-carcinogenic } \\
\text { elements }\end{array}$} & $\mathrm{Hg}$ & $\mathrm{Pb}$ & - & 2.00 & 329.05 & - & - \\
& $\mathrm{Cr}$ & - & - & - & $3.00 \times 10^{-4}$ & $2.10 \times 10^{-5}$ & $7.66 \times 10^{-5}$ \\
& & - & - & $3.50 \times 10^{-4}$ & $5.25 \times 10^{-4}$ & $3.52 \times 10^{-2}$ \\
\end{tabular}

Note: SFo means oral intake carcinogenic slope factor. SFd means skin contact carcinogenic slope factor. SFi means inhalation carcinogenic slope factor. RfDo means oral intake reference dose. RfDd means skin contact reference dose. RfDi means inhalation reference dose.

Table A4. Parameters of indicator semivariograms theoretical models for variables.

\begin{tabular}{cccccccc}
\hline Element & Quantile & $\begin{array}{c}\text { Threshold } \\
(\mathbf{m g} / \mathbf{k g})\end{array}$ & $\mathbf{C}_{\mathbf{0}}$ & $\mathbf{C}_{\mathbf{0}}+\mathbf{C}_{\mathbf{1}}$ & $\begin{array}{c}\text { Fitted } \\
\text { Model }\end{array}$ & Range(m) & $\mathbf{R}^{\mathbf{2}}$ \\
\hline \multirow{3}{*}{$\mathrm{Cd}$} & 0.25 & 0.1440 & 0.1182 & 0.2704 & Exponential & 24,380 & 0.80 \\
& 0.5 & 0.1751 & 0.0710 & 0.2560 & Gaussian & 2760 & 0.90 \\
& 0.75 & 0.2208 & 0.0560 & 0.171 & Gaussian & 2060 & 0.91 \\
\hline \multirow{3}{*}{$\mathrm{Hg}$} & 0.25 & 0.0776 & 0.0001 & 0.1982 & Exponential & 1530 & 0.70 \\
& 0.5 & 0.1057 & 0.0082 & 0.2484 & Exponential & 1270 & 0.83 \\
& 0.75 & 0.1520 & 0.0569 & 0.1938 & Spherical & 21,920 & 0.96 \\
\hline \multirow{2}{*}{$\mathrm{AS}$} & 0.25 & 4.4085 & 0.0187 & 0.2014 & Spherical & 3210 & 0.65 \\
& 0.5 & 8.1937 & 0.1001 & 0.2962 & Exponential & 7460 & 0.95 \\
$\mathrm{Hb}$ & 0.75 & 12.6000 & 0.0419 & 0.1948 & Spherical & 17,490 & 0.98 \\
\hline \multirow{2}{*}{$\mathrm{Cr}$} & 0.25 & 41.7199 & 0.1280 & 0.4010 & Exponential & 71,100 & 0.83 \\
& 0.5 & 48.9496 & 0.1194 & 0.2548 & Exponential & 2850 & 0.88 \\
& 0.75 & 57.9000 & 0.0607 & 0.1834 & Exponential & 1350 & 0.73 \\
\hline
\end{tabular}

\section{References}

1. Foley, J.A.; DeFries, R.; Asner, G.P.; Barford, C.; Bonan, G.; Carpenter, S.R.; Chapin, F.S.; Coe, M.T.; Daily, G.C.; Gibbs, H.K.; et al. Global consequences of land use. Science 2005, 309, 570-574. [CrossRef]

2. Zhao, F.J.; Ma, Y.; Zhu, Y.G.; Tang, Z.; McGrath, S.P. Soil contamination in China: Current status and mitigation strategies. Environ. Sci. Technol. 2015, 49, 750-759. [CrossRef]

3. Zhao, H.; Xia, B.; Fan, C.; Zhao, P.; Shen, S. Human health risk from soil heavy metal contamination under different land uses near Dabaoshan Mine, Southern China. Sci. Total Environ. 2012, 417-418, 45-54. [CrossRef]

4. Järup, L. Hazards of heavy metal contamination. Br. Med. Bull. 2003, 68, 167-182. [CrossRef] [PubMed]

5. Lee, C.S.L.; Li, X.; Shi, W.; Cheung, S.C.N.; Thornton, I. Metal contamination in urban, suburban, and country park soils of Hong Kong: A study based on GIS and multivariate statistics. Sci. Total Environ. 2006, 356, 45-61. [CrossRef] [PubMed]

6. Cicchella, D.; DeVivo, B.; Lima, A.; Albanese, S.; McGill, R.A.R.; Parrish, R.R. Heavy metal pollution and Pb isotopes in urban soils of Napoli, Italy. Geochem. Explor. Environ. Anal. 2008, 8, 103-112. [CrossRef]

7. Sawut, R.; Kasim, N.; Maihemuti, B.; Hu, L.; Abliz, A.; Abdujappar, A.; Kurban, M. Pollution characteristics and health risk assessment of heavy metals in the vegetable bases of northwest China. Sci. Total Environ. 2018, 642, 864-878. [CrossRef] [PubMed]

8. Ho, Y.B.; Abdullah, N.H.; Hamsan, H.; Tan, E.S.S. Mercury contamination in facial skin lightening creams and its health risks to user. Regul. Toxicol. Pharmacol. 2017, 88, 72-76. [CrossRef]

9. Zukowska, J.; Biziuk, M. Methodological evaluation of method for dietary heavy metal intake. J. Food Sci. 2008, 73, R21-R29. [CrossRef] 
10. Khan, A.G.; Kuek, C.; Chaudhry, T.M.; Khoo, C.S.; Hayes, W.J.; Wong, M.H. Role of plants, mycorrhizae and phytochelators in heavy metal contaminated land remediation. Chemosphere 2000, 41, 197-207. [CrossRef]

11. Yi, Y.; Yang, Z.; Zhang, S. Ecological risk assessment of heavy metals in sediment and human health risk assessment of heavy metals in fishes in the middle and lower reaches of the Yangtze River basin. Environ. Pollut. 2011, 159, 2575-2585. [CrossRef] [PubMed]

12. Gay, J.R.; Korre, A. A spatially-evaluated methodology for assessing risk to a population from contaminated land. Environ. Pollut. 2006, 142, 227-234. [CrossRef] [PubMed]

13. Khan, S.; Cao, Q.; Zheng, Y.M.; Huang, Y.Z.; Zhu, Y.G. Health risks of heavy metals in contaminated soils and food crops irrigated with wastewater in Beijing, China. Environ. Pollut. 2008, 152, 686-692. [CrossRef] [PubMed]

14. Zhao, Y.; Xu, X.; Sun, W.; Huang, B.; Darilek, J.L.; Shi, X. Uncertainty assessment of mapping mercury contaminated soils of a rapidly industrializing city in the Yangtze River Delta of China using sequential indicator co-simulation. Environ. Monit. Assess. 2008, 138, 343-355. [CrossRef] [PubMed]

15. Zhuang, P.; McBride, M.B.; Xia, H.; Li, N.; Li, Z. Health risk from heavy metals via consumption of food crops in the vicinity of Dabaoshan mine, South China. Sci. Total Environ. 2009, 407, 1551-1561. [CrossRef] [PubMed]

16. Man, Y.B.; Sun, X.L.; Zhao, Y.G.; Lopez, B.N.; Shanshan, C.; Wu, S.C.; Kwaichung, C.; Wong, M.H. Health risk assessment of abandoned agricultural soils based on heavy metal contents in Hong Kong, the world's most populated city. Environ. Int. 2010, 36, 570-576. [CrossRef]

17. Li, P.; Lin, C.; Cheng, H.; Duan, X.; Lei, K. Contamination and health risks of soil heavy metals around a lead/zinc smelter in southwestern China. Ecotoxicol. Environ. Saf. 2015, 113, 391-399. [CrossRef]

18. Gu, Y.G.; Gao, Y.P.; Lin, Q. Contamination, bioaccessibility and human health risk of heavy metals in exposed-lawn soils from 28 urban parks in southern China's largest city, Guangzhou. Appl. Geochem. 2016, 67, 52-58. [CrossRef]

19. MEPPRC. Technical Guidelines for Risk Assessment of Contaminated Sites (HJ25.3-2014, Published in Chinese); China Environmental Science Press: Beijing, China, 2014.

20. Chen, H.; Teng, Y.; Lu, S.; Wang, Y.; Wu, J.; Wang, J. Source apportionment and health risk assessment of trace metals in surface soils of Beijing metropolitan, China. Chemosphere 2015, 144, 1002. [CrossRef]

21. Schuhmacher, M.; Meneses, M.; Xifró, A.; Domingo, J.L. The use of Monte-Carlo simulation techniques for risk assessment: study of a municipal waste incinerator. Chemosphere 2001, 43, 787. [CrossRef]

22. Sonnemann, G.W.; Pla, Y.; Schuhmacher, M.; Castells, F. Framework for the uncertainty assessment in the Impact Pathway Analysis with an application on a local scale in Spain. Environ. Int. 2002, 28, 9-18. [CrossRef]

23. Pyrcz, M.J.; Deutsch, C. V Geostatistical Reservoir Modeling; Oxford University Press: New York, NY, USA, 2014; ISBN 0199731446.

24. Albuquerque, M.T.D.; Gerassisc, S.; Sierrad, C.; Taboadac, J.; Martínc, J.E.; Antuneseb, I.M.H.R. Developing a new Bayesian Risk Index for risk evaluation of soil contamination. Sci. Total Environ. 2017, 603-604, 167-177. [CrossRef] [PubMed]

25. Goovaerts, P. Geostatistics for Natural Resources Evaluation; Oxford University Press: New York, NY, USA, 1997.

26. Duzgorenaydin, N.S.; Wong, C.S.; Aydin, A.; Song, Z.; You, M.; Li, X.D. Heavy metal contamination and distribution in the urban environment of Guangzhou, SE China. Environ. Geochem. Health 2006, 28, 375-391. [CrossRef] [PubMed]

27. Li, J.H.; Ying, L.; Wei, Y.; Gan, H.H.; Chao, Z.; Deng, X.L.; Jin, L. Distribution of heavy metals in agricultural soils near a petrochemical complex in Guangzhou, China. Environ. Monit. Assess. 2009, 153, 365-375. [CrossRef] [PubMed]

28. Cai, Q.Y.; Mo, C.H.; Li, H.Q.; Lü, H.; Zeng, Q.Y.; Li, Y.W.; Wu, X.L. Heavy metal contamination of urban soils and dusts in Guangzhou, South China. Environ. Monit. Assess. 2013, 185, 1095-1106. [CrossRef]

29. Goovaerts, P. Geostatistical modelling of uncertainty in soil science. Geoderma 2001, 103, 3-26. [CrossRef]

30. Juang, K.W.; Chen, Y.S.; Lee, D.Y. Using sequential indicator simulation to assess the uncertainty of delineating heavy-metal contaminated soils. Environ. Pollut. 2004, 127, 229-238. [CrossRef]

31. Huang, J.; Liu, W.; Zeng, G.; Li, F.; Huang, X.; Gu, Y.; Shi, L.; Shi, Y.; Wan, J. An exploration of spatial human health risk assessment of soil toxic metals under different land uses using sequential indicator simulation. Ecotoxicol. Environ. Saf. 2016, 129, 199-209. [CrossRef]

32. Deutsch, C.V.; Journel, A.G. GSLIB: Geostatistical Software Library and User's Guide, 2nd ed.; Oxford University Press: New York, NY, USA, 1998. 
33. Cattle, J.A.; McBratney, A.; Minasny, B. Kriging method evaluation for assessing the spatial distribution of urban soil lead contamination. J. Environ. Qual. 2002, 31, 1576-1588. [CrossRef]

34. Chen, H.; Teng, Y.; Lu, S.; Wang, Y.; Wang, J. Contamination features and health risk of soil heavy metals in China. Sci. Total Environ. 2015, 512, 143-153. [CrossRef]

35. US EPA. Proposed Guidelines for Carcinogen Risk Assessment. Fed. Regist. 1996, 61, 17960-18011.

36. Pawełczyk, A.; Božek, F.; Grabas, K. Impact of military metallurgical plant wastes on the population's health risk. Chemosphere 2016, 152, 513-519. [CrossRef] [PubMed]

37. Katz, S.A.; Salem, H. The Biological and Environmental Chemistry of Chromium; Wiley Sons: Hoboken, NJ, USA, 1994.

38. US EPA Regional Screening Levels (RSLs). Available online: https://www.epa.gov/risk/regional-screeninglevels-rsls (accessed on 1 December 2018).

39. Yang, Y.; Christakos, G. Uncertainty assessment of heavy metal soil contamination mapping using spatiotemporal sequential indicator simulation with multi-temporal sampling points. Environ. Monit. Assess. 2015, 187, 571. [CrossRef] [PubMed]

40. AQTSGP. Risk Screening Values for Soil Heavy Metal The Pearl River Delta Area (DB 44/ T1415-2014, Published in Chinese); Guangdong Quality and Technical Supervision Bureau: Guangzhou, China, 2014.

41. Li, F.; Huang, J.; Zeng, G.; Liu, W.; Huang, X.; Huang, B.; Gu, Y.; Shi, L.; He, X.; He, Y. Toxic metals in topsoil under different land uses from Xiandao District, middle China: distribution, relationship with soil characteristics, and health risk assessment. Environ. Sci. Pollut. Res. Int. 2015, 22, 12261-12275. [CrossRef]

42. Yao, R.; Yang, J.; Han, J. Stochastic simulation and uncertainty assessment of spatial variation in soil salinity in coastal reclamation regions. Zhongguo Shengtai Nongye Xuebao/Chinese J. Eco-Agriculture 2011, 19, 485-490. [CrossRef]

43. Wang, S.; Cao, X.; Lin, C.; Chen, X. Arsenic content and fractionation in the surface sediments of the Guangzhou section of the Pearl River in Southern China. J. Hazard. Mater. 2010, 183, 264-270. [CrossRef]

44. Han, L.; Gao, B.; Hao, H.; Lu, J.; Xu, D. Arsenic pollution of sediments in China: An assessment by geochemical baseline. Sci. Total Environ. 2019, 651, 1983-1991. [CrossRef]

45. Huang, M.; Wang, W.; Chan, C.Y.; Cheung, K.C.; Man, Y.B.; Wang, X.; Wong, M.H. Contamination and risk assessment (based on bioaccessibility via ingestion and inhalation) of metal (loid) $\mathrm{s}$ in outdoor and indoor particles from urban centers of Guangzhou, China. Sci. Total Environ. 2014, 479, 117-124. [CrossRef]

46. Gu, Y.G.; Gao, Y.P. Bioaccessibilities and health implications of heavy metals in exposed-lawn soils from 28 urban parks in the megacity Guangzhou inferred from an in vitro physiologically-based extraction test. Ecotoxicol. Environ. Saf. 2018, 148, 747-753. [CrossRef]

47. Duzgoren-Aydin, N.S. Sources and characteristics of lead pollution in the urban environment of Guangzhou. Sci. Total Environ. 2007, 385, 182-195. [CrossRef]

48. Pariente, S.; Helena, Z.; Eyal, S.; Anatoly, F.G.; Michal, Z. Road side effect on lead content in sandy soil. Catena 2019, 174, 301-307. [CrossRef]

49. Lu, J.; Ma, L.; Cheng, C.; Pei, C.; Chan, C.K.; Bi, X.; Qin, Y.; Tan, H.; Zhou, J.; Chen, M. Real time analysis of lead-containing atmospheric particles in Guangzhou during wintertime using single particle aerosol mass spectrometry. Ecotoxicol. Environ. Saf. 2019, 168, 53-63. [CrossRef] [PubMed]

50. Bi, C.; Zhou, Y.; Chen, Z.; Jia, J.; Bao, X. Heavy metals and lead isotopes in soils, road dust and leafy vegetables and health risks via vegetable consumption in the industrial areas of Shanghai, China. Sci. Total Environ. 2018, 619, 1349-1357. [CrossRef] [PubMed]

51. Li, C.; Sun, G.; Wu, Z.; Zhong, H.; Wang, R.; Liu, X.; Guo, Z.; Cheng, J. Soil physiochemical properties and landscape patterns control trace metal contamination at the urban-rural interface in southern China. Environ. Pollut. 2019, 250, 537-545. [CrossRef] [PubMed]

52. Huang, M.; Chen, X.; Shao, D.; Zhao, Y.; Wang, W.; Wong, M.H. Risk assessment of arsenic and other metals via atmospheric particles, and effects of atmospheric exposure and other demographic factors on their accumulations in human scalp hair in urban area of Guangzhou, China. Ecotoxicol. Environ. Saf. 2014, 102, 84-92. [CrossRef] [PubMed]

53. Huang, M.; Wang, W.; Leung, H.; Chan, C.Y.; Liu, W.K.; Wong, M.H.; Cheung, K.C. Mercury levels in road dust and household TSP/PM2. 5 related to concentrations in hair in Guangzhou, China. Ecotoxicol. Environ. Saf. 2012, 81, 27-35. [CrossRef] 
54. Xiao, S.; Zhao, Y.; Wang, B. Problem analysis of geological properties evaluation using indicator Kriging. Petrochem. Ind. Appl. 2013.

55. Antunes, I.M.H.R.; Albuquerque, M.T.D. Using indicator kriging for the evaluation of arsenic potential contamination in an abandoned mining area (Portugal). Sci. Total Environ. 2013, 442, 545-552. [CrossRef]

56. Journel, A.G. Nonparametric estimation of spatial distributions. J. Int. Assoc. Math. Geol. 1983, 15, 445-468. [CrossRef]

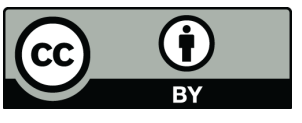

(C) 2020 by the authors. Licensee MDPI, Basel, Switzerland. This article is an open access article distributed under the terms and conditions of the Creative Commons Attribution (CC BY) license (http://creativecommons.org/licenses/by/4.0/). 